\title{
Evaluation of combined vaccinia virus-mediated antitumor gene therapy with p53, IL-2, and IL-12 in a glioma model
}

\author{
Bing Chen, ${ }^{1,2}$ Tatyana M. Timiryasova, ${ }^{1}$ Melba L. Andres, ${ }^{3}$ Eric H. Kajioka, ${ }^{3}$ \\ Radha Dutta-Roy, ${ }^{3}$ Daila S. Gridley, ${ }^{2,3}$ and Istvan Fodor ${ }^{1,2}$
}

${ }^{1}$ Center for Molecular Biology and Gene Therapy; ${ }^{2}$ Departments of Microbiology and Molecular Genetics; and ${ }^{3}$ Radiation Medicine, Loma Linda University School of Medicine, Loma Linda, California.

Our previous studies have shown that vaccinia virus (VV) expressing p53, interleukin-2 (IL-2), and interleukin-12 (IL-12) results in an effective inhibition of subcutaneous glioma growth in mice. We propose that combination therapy of tumors with virusmediated p53 and cytokine genes offers the prospect of synergistic antitumor response. In this work, the antitumor efficacy of $\mathrm{V} V$ mediated combination of p53, IL-2, and IL-12 genes was evaluated in a nude mouse model. To minimize cytokine-associated toxicity, a virus dose as low as 10 plaque-forming units of VV expressing IL - 2 and IL - 12 per animal was used alone and together with $2 \times 10^{7}$ plaque-forming units of $\mathrm{VV}$ expressing $\mathrm{p} 53$. Intratumoral treatment of established C6 glioma with recombinant viruses $\mathrm{rVV}$ p53, rVV-mIL2, rVV-mIL12, and rVV-2-12 induced the prolonged expression of p53, IL-2, IL-12, and both cytokines simultaneously. The combination of rVV-p53/rVV-mIL12 or rVV-p53/rVV-2-12 resulted in significant tumor inhibition compared to single modality treatment $(P<.05)$. rVV-p53/rVV-2-12 therapy was associated with significant elevation of natural killer, Mac $1^{+}$, and NKT cells in blood and interferon $-\gamma$ and tumor necrosis factor - $\alpha$ expression in tumors. The difference in the inhibition of tumor growth between the rVV-p53/rVV-mIL2 combination and rVV-p53 was statistically insignificant. These data demonstrate that gene therapy based on VV-mediated combination of p53, IL - 2, and IL-12 treatment may be a promising adjunctive strategy for glioma treatment. Cancer Gene Therapy (2000) 7, 1437-1447

Key words: Vaccinia virus; p53; IL-2; IL-12; glioma; gene therapy.

G lioblastoma, a tumor derived from glial precursors, is the most common primary tumor of the central nervous system in adults. The median survival time for patients with these and other high-grade tumors of the central nervous system is less than 1 year. ${ }^{1}$ Mutations in $\mathrm{p} 53$ have been found in $63-65 \%$ of high-grade and $63 \%$ of low-grade astrocytomas. $^{2,3}$ The documented functions of p53 include cell growth arrest that is partially mediated by $\mathrm{p} 21$ up-regulation and the induction of apoptosis that may involve the apoptosis -regulating genes, $\mathrm{Bcl}-2$ and $\mathrm{Bax}^{4}{ }^{4}$ Several studies have demonstrated that virus-mediated delivery of wildtype p53 can suppress the growth of a number of human cancer cell lines in vitro and in vivo. ${ }^{5-8}$ Therefore, therapeutic strategies designed to restore wild-type p53 protein activity in cancer cells are particularly appealing.

Recently, it has been demonstrated that delivery and overexpression of wild-type p53 gene-induced apoptosis in rat and human glioma cell lines in vitro ${ }^{9-11}$ can be independent of endogenous p53 status. ${ }^{11,12}$ p53 transduced

Received May 24, 2000; accepted August 5, 2000.

Address correspondence and reprint requests to Istvan Fodor, Center for Molecular Biology and Gene Therapy, Mortensen Hall, Loma Linda University School of Medicine, 11085 Campus Street, Loma Linda, CA 92350. E-mail address: ifodor@som.llu.edu into established intracranial rat 9L glioma suppressed tumor growth by $40 \%{ }^{13}$ In a nude mouse model, injection of adenovirus ${ }^{14}$ or vaccinia virus (VV) ${ }^{15}$ expressing p53 also resulted in effective inhibition of glioma growth. Although these studies demonstrated the potential of p53 gene therapy, the efficacy of the treatment is far from ideal, and further improvements in this anticancer strategy are needed. For example, administration of multiple therapeutic modalities may provide a more effective approach for treatment of cancer. Indeed, it was demonstrated that overexpressed p53 rendered the tumor cells more sensitive to radiation ${ }^{16,17}$ and cisplatin-induced apoptosis, ${ }^{18}$ whereas each agent alone either failed to achieve a significant antitumor effect or slowed tumor growth only modestly. Other therapeutic genes, like those encoding cytokines, combined with p53 treatment may also augment an antitumor effect. Recently, Putzer et al ${ }^{19}$ have shown that combined delivery of p53 and interleukin-2 (IL-2) genes into murine breast tumors resulted in significant tumor regression in $65 \%$ of animals. IL - 2 and interleukin-12 (IL-12) are potent agents that have been demonstrated to possess antitumor activity through their ability to stimulate cytotoxic T lymphocytes, to enhance natural killer (NK) cell activity, and to activate tumorinfiltrating lymphocytes. $^{20-22}$ In addition, the IL-12mediated antitumor effect is also related to its antiangiogenic properties and ability to increase interferon- $\gamma($ IFN $-\gamma)$ 
secretion. ${ }^{23}$ Previous studies ${ }^{24,25}$ in both xenogenic and syngeneic glioma models have shown that intratumoral (i.t.) IL-2 production may stimulate an immune antitumor response with the predominance of $\mathrm{CD}^{+}$and $\mathrm{CD} 8^{+}$ lymphocytes, NK cells, neutrophils, and activated macrophages. IL- 12 has been recently shown to induce antiglioma immune activity in rodent models. ${ }^{26-28}$

To increase the efficacy of antitumor therapy, we are studying VVs as vectors for gene therapy. Recently, we have shown that VV expressing p53 (rVV-p53) was effective in tumor therapy of nude mice in ex vivo experiments and in a subcutaneous (s.c.) glioma model. ${ }^{15}$ We also found that VV carrying either the mouse IL-2 (rVV-mIL2) or IL-12 (rVV-mIL12) gene could induce significant tumor inhibition in a pre-established C6 glioma model even when the viral dose was as low as 100 plaque-forming units $(\mathrm{pfu}){ }^{29}$ However, like most other cytokine therapies, toxicity is a major limitation of the strategy. To achieve better antitumor efficacy and minimize the risk for cytokine toxicity, we investigated in the present study the effects of treatment with combinations of low-dose rVV-mIL2 or rVV-mIL12 and highdose rVV-p53 in a C6 glioma model. Treatment with recombinant viruses, combined at a ratio of $10: 2 \times 10^{7}$ pfu, effectively expressed their transgenes in vivo and synergistically inhibited tumor growth. In addition, the data support the premise that the underlying mechanisms of action included recruitment of NK cells and induction of IFN- $\gamma$.

\section{MATERIALS AND METHODS}

\section{$\checkmark V$ constructs}

Construction and characterization of recombinant virus rVV2, rVV4, rVV-p53, rVV-mIL2, rVV-mIL12, and VV containing both IL-2 and IL-12 genes (rVV-2-12) were performed as previously described. ${ }^{15,29}$ rVV2 was the control virus for rVV-p53, whereas rVV4 was the control for recombinant viruses carrying genes encoding cytokines. Instead of a therapeutic gene, in rVV2 and rVV4, reporter genes lacZ of Escherichia coli and firefly luciferase $(l u c)$ were inserted into the same position of the genome that carried the therapeutic genes in recombinant viruses.

\section{Cell lines and animals}

CV-1 cells, African green monkey kidney fibroblasts, were obtained from the American Type Culture Collection (ATCC, Rockville, MD), maintained in Dulbecco's modified Eagle's medium, and used to propagate the rVV constructs. The rat C6 nitrosourea-induced glioma cell line, originally established by Benda et $\mathrm{al}^{30}{ }^{30}$ was cultured in RPMI-1640 medium (Cellgro/Mediatech, Herndon, VA). Both media were supplemented with $5 \%$ fetal bovine serum and antibiotic-antimycotic solution (Sigma, St. Louis, MO).

Athymic nude mice (male; $n=124$ ) were obtained from Charles River Breeding Laboratories (Wilmington, MA) at 4-6 weeks of age and acclimatized for at least 2 weeks before study initiation. All animal experiments were approved and conducted in accordance with the animal care policies of Loma Linda University.

\section{Infection of cells in vitro}

To determine whether coinfection with two different rVVs would result in interference with the expression of one or the other of the transgenes, equal amounts of rVV-p53 and rVV-mIL2 were used to infect C6 glioma cells in vitro at a multiplicity of infection (MOI) of $0.2 \mathrm{pfu} / \mathrm{cell}$. The virus was added to the cell monolayer $\left(1 \times 10^{6}\right.$ cells/ well) and incubated at $37^{\circ} \mathrm{C}$ for 1 hour. Complete RPMI 1640 medium was then added, and samples at specific time points were taken and frozen at $-80^{\circ} \mathrm{C}$. The level of IL - 2 secreted into the medium was measured by enzymelinked immunosorbent assay (ELISA) using a mouse IL2 Duoset $^{(\mathbb{}}{ }^{\text {kit }}$ (Genzyme, Cambridge, MA). p53 expression was detected by Western blot as previously described. ${ }^{11}$

Because the ratio of cytokine- and $\mathrm{p} 53$-producing viruses was $10: 2 \times 10^{7} \mathrm{pfu}$ in the combined therapy, we did not rule out the possibility that high-dose virus could inhibit the infection and replication of the low-dose virus. To test this possibility, C6 cells were coinfected with rVV4 expressing the lacZ gene and wild-type VV (wtVV) at a ratio 1:100. Cells were then fixed with $2 \%$ formaldehyde ( $\mathrm{vol} / \mathrm{vol}$ ) and $0.2 \%$ glutaraldehyde ( $\mathrm{vol} / \mathrm{vol})$ in phosphate-buffered salines (PBS) for 30 minutes. Fixed cells were washed two times with PBS and stained in X-gal solution for 4 hours at $37^{\circ} \mathrm{C}$. X-gal solution contained $5 \mathrm{mM}$ potassium ferricyanide, $5 \mathrm{mM}$ potassium ferrocyanide, $2 \mathrm{mM} \mathrm{MgCl} 2$, $1 \mathrm{mg} / \mathrm{mL} \mathrm{X}$-gal in PBS.

The level of lacZ gene expression was also determined by chemoluminescent assay. C6 cells were coinfected with $\mathrm{wtVV}$ and/or rVV4 as described above. Cells were lysed 24 hours later in lysis buffer and assayed using the Galactolight Plus ${ }^{\circledR}$ kit (Tropix, Bedford, MA). Bioluminescence

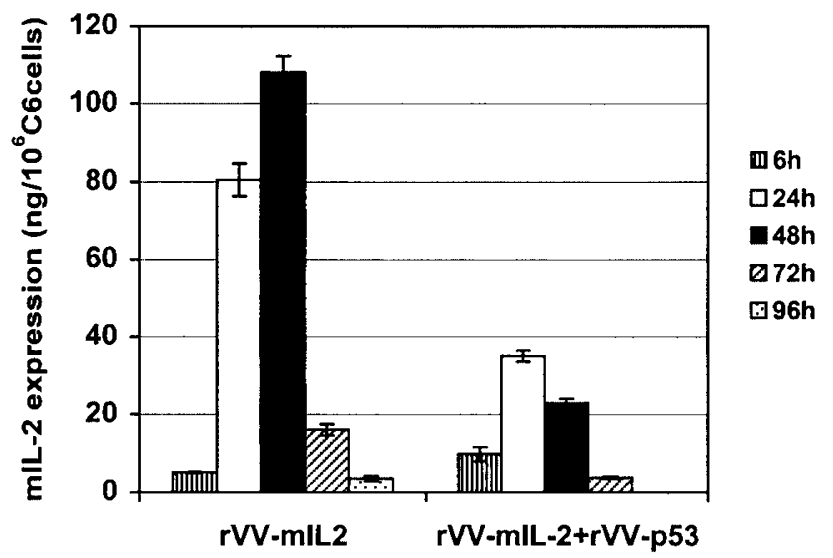

Figure 1. IL-2 expression in cells coinfected with rVV-p53/rVVmIL2 in vitro. C6 glioma cells $\left(1 \times 10^{6} /\right.$ well $)$ were dispensed into sixwell plates and infected with rVV-mIL2 or rVV-p53/rVV - mIL2 at 0.2 pfu of each virus. Supernatants were collected at $6,24,48,72$, and 96 hours and measured for IL-2 by ELISA. 


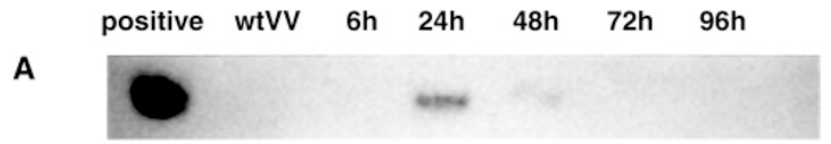

B

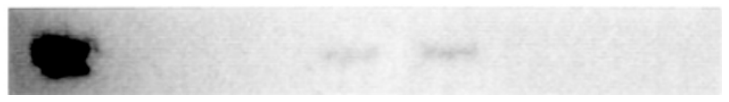

Figure 2. p53 expression in cells coinfected with rVV - p53/rVV-mIL2 in vitro. C6 glioma cells $\left(1 \times 10^{6} /\right.$ well $)$ were dispensed into six - well plates and infected with rVV-mIL2 (A) or rVV-p53/rVV-mIL2 (B) at $0.2 \mathrm{pfu}$ of each virus. Cells were harvested and homogenized in lysis buffer at $6,24,48,72$, and 96 hours. Proteins $(80 \mu \mathrm{g})$ were separated by $12 \%$ sodium dodecyl sulfate-polyacrylamide gel electrophoresis and probed with primary antibody (DO-7, Vector Laboratories). The blot was then incubated with horseradish peroxidase-conjugated secondary antibody and developed in color regent. p53 expression by the SW480 cell line served as positive control and wild-type VV served as negative control.

was measured by ML300 microplate luminometer (Dynatech Laboratories, Chantilly, VA).

\section{Functional assay of p53}

The p53 function was analyzed by DNA fragmentation assay. C6 cells were plated in $10-\mathrm{cm}^{2}$ dishes at $9 \times 10^{6}$ cells/dish 24 hours before virus infection. Cells were then infected with rVV2, rVV4, rVV2/rVV4, rVV-mIL2, rVV-p53, and rVV-p53/rVV-mIL2 with 0.2 pfu of each virus. The cells were harvested at 48 hours postinfection and lysed in $10 \mathrm{mM}$ Tris- $\mathrm{HCl} \mathrm{pH} 7.5,1 \mathrm{mM}$ EDTA, and $0.2 \%$ Triton X-100. After incubation on ice for 50 minutes, debris was centrifuged and supernatant was sequentially digested with $400 \mu \mathrm{g} / \mathrm{mL}$ RNase and 400 $\mu \mathrm{g} / \mathrm{mL}$ Protease $\mathrm{K}$ for 30 minutes at $37^{\circ} \mathrm{C}$. Samples were then extracted with phenol/chloroform/isoamyl alcohol for three times. DNA was precipitated and dissolved in $30 \mu \mathrm{L} \mathrm{H}_{2} \mathrm{O}$, and $4 \mu \mathrm{g}$ of DNA from each sample was analyzed by electrophoresis in $2 \%$ agarose gel.

\section{Tumor growth in vivo}

An aliquot of $5 \times 10^{5} \mathrm{C} 6$ glioma cells was injected s.c. in the right hind leg of athymic nude mice. Animals were then randomly divided into 11 groups $(n=8-12 /$ group $)$ :

A

wtVV 1 PFU

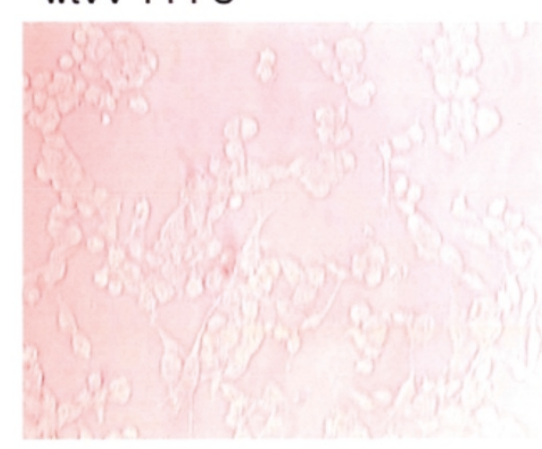

rVV4 0.01 PFU

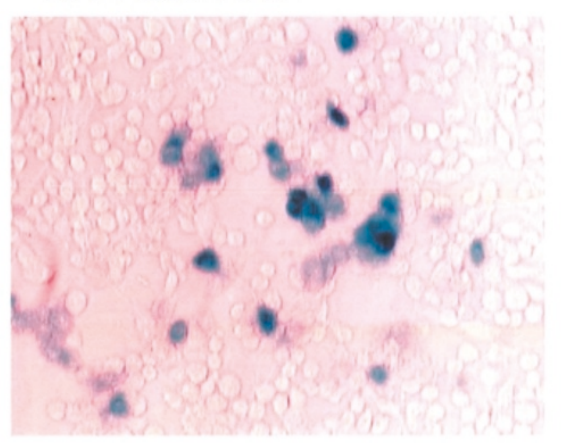

wtVV 1 PFU + rVV4 0.01 PFU

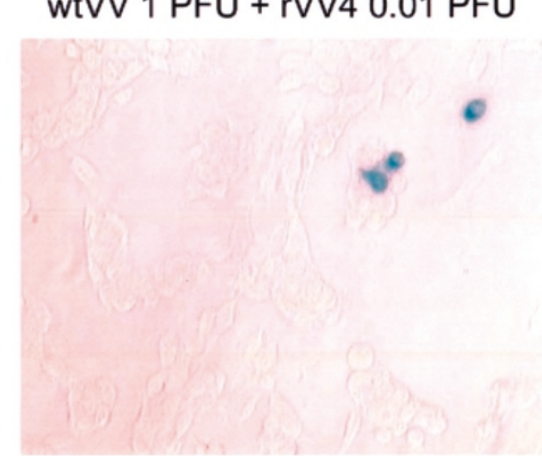

B

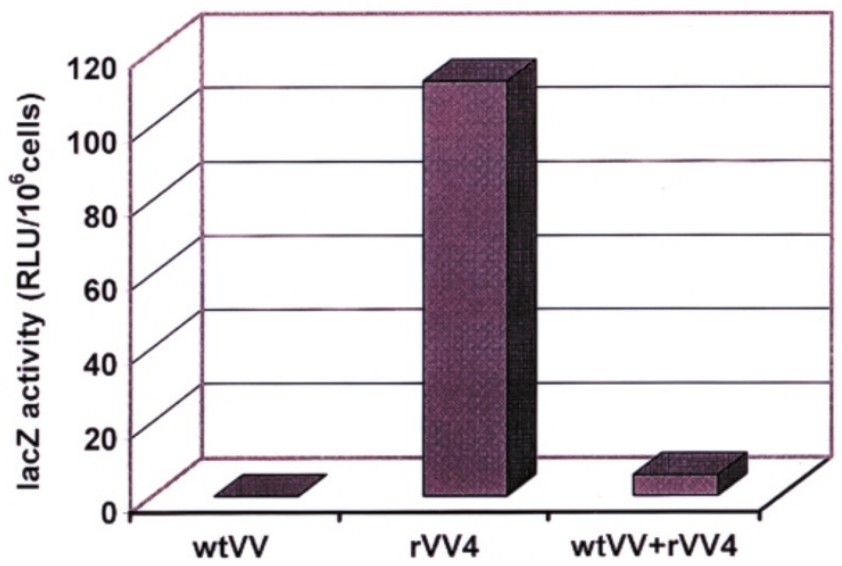

Figure 3. The lacZexpression in C6 cells co-infected with wtVV/ rVV4. C6 glioma cells were infected with wtVV, rVV4, or wtVV/ rVV4 at indicated $\mathrm{MOI}$. Twenty-four hours later, lacZ production was visualized by $\mathrm{X}$-gal staining $(\mathbf{A})$ and the level of expression was measured by a chemoluminescence method (B). 
normal nontumor-bearing control, Hanks' buffered saline-treated tumor-bearing control, rVV4 control, rVV2 control, rVV-mIL2, rVV-mIL12, rVV-2-12, rVV-p53, rVV-p53/rVV-mIL2, rVV-p53/rVV-mIL12, and rVVp53/rVV-2-12. Approximately 5 days later, when palpable tumors had developed in tumor cell-injected recipients, a single i.t. injection of Hanks' solution, 10 pfu of rVV4, or cytokine recombinant VV was performed in a volume of $50 \mu \mathrm{L}$. Twenty-four hours later, mice in the appropriate treatment groups received rVV2 or rVVp53 at the dose of $2 \times 10^{7}$ pfu. Animals were weighed twice a week; tumor dimensions were measured with calipers. Subsets of mice from each group were euthanized at 4 and 9 days after treatment. At the 4day time point, gene expression was expected to be well underway, whereas the 9-day time point was selected because mean tumor volume in the saline-treated control group had reached the maximum allowed $\left(\sim 2500 \mathrm{~mm}^{3}\right)$. Tumors from mice euthanized on days 4 and 9 were excised and one half was fixed in $10 \%$ buffered formalin. The remaining portion was snap frozen in liquid nitrogen and stored at $-80^{\circ} \mathrm{C}$.

\section{Detection of p53 and cytokine expression in tumors}

Frozen tumors were thawed and cut into small pieces in PBS with $100 \mu \mathrm{M}$ phenylmethylsulfonyl fluoride. After centrifugation at $358 \times g$ for 5 minutes, supernatant was collected and assayed for IL-2, IL-12 (Duoset ${ }^{(\mathrm{IM})}$ kit, Genzyme), IFN- $\gamma$, and TNF- $\alpha$ (Quantikine ${ }^{(i I}$, R\&D Systems, Minneapolis, MN) expression by ELISA.

The p53 expression was detected by immunohistochemistry as previously described. ${ }^{15}$ Briefly, formalin-fixed tumors were embedded in paraffin and sectioned $(5 \mu \mathrm{m})$. Monoclonal antibody against human p53 (1:100, clone DO-7, Novocastra Lab, Newcastle, UK) and Cy 3conjugated antimouse antibody (1:1000, Jackson Immuno-Research Laboratories, West Grove, PA) were used as primary and secondary antibodies, respectively. After immunohistochemical reactions, sections were counterstained with 4',6-diamidine-2-phenylindole dihydrochloride for nuclear detection. Expression of p53 was analyzed using fluorescence microscopy.

\section{In situ TUNEL assay}

Apoptosis-associated DNA cleavages were detected using terminal deoxynucleotidyl transferase-mediated dUTP nick end-labeling of DNA (TUNEL, in situ cell death detection kit, fluorescein, Boehringer Mannheim, Indianapolis, IN). Tumor sections on day 9 after virus infection were deparaffinized and permeabilized with $0.1 \%$ Triton $\mathrm{X}-100$ in $0.1 \%$ sodium citrate for 2 minutes on ice. After several washes in PBS, the sections were incubated with the TUNEL reaction mixture containing fluorescein-conjugated dUTP for 60 minutes at $37^{\circ} \mathrm{C}$ in the dark as specified by the manufacturer (Boehringer Mannheim). Following three washes with PBS, samples were directly analyzed using a fluorescence microscope.

\section{Flow cytometry analysis}

Four and 9 days after virus infection, a whole blood sample from each animal was collected in heparinized tuberculin syringes via cardiac puncture immediately after euthanasia. Spleens were removed and smashed in RPMI-1640 medium before filtration. The leukocyte counts in blood and spleen were determined using an ABC Vet Hematology Analyzer (Heska, Waukesha, WI). An aliquot $(50 \mu \mathrm{L})$ of each sample was then stained with appropriate fluorescence-conjugated monoclonal antibodies against the following markers: CD45 (all leukocytes), CD19 (B cells), pan-NK (NK cells), NK1.1/TCR - $\beta$ (NKT cells), and Mac-1 (all phagocytes) (PharMingen, San Diego, CA). Stained cells were washed and analyzed using standard procedures and a FACSCalibur $^{(\mathrm{II})}$ flow cytometer with CellQuest ${ }^{(\mathrm{II})}$ software version 3.1 (Becton Dickinson, San Diego, CA).
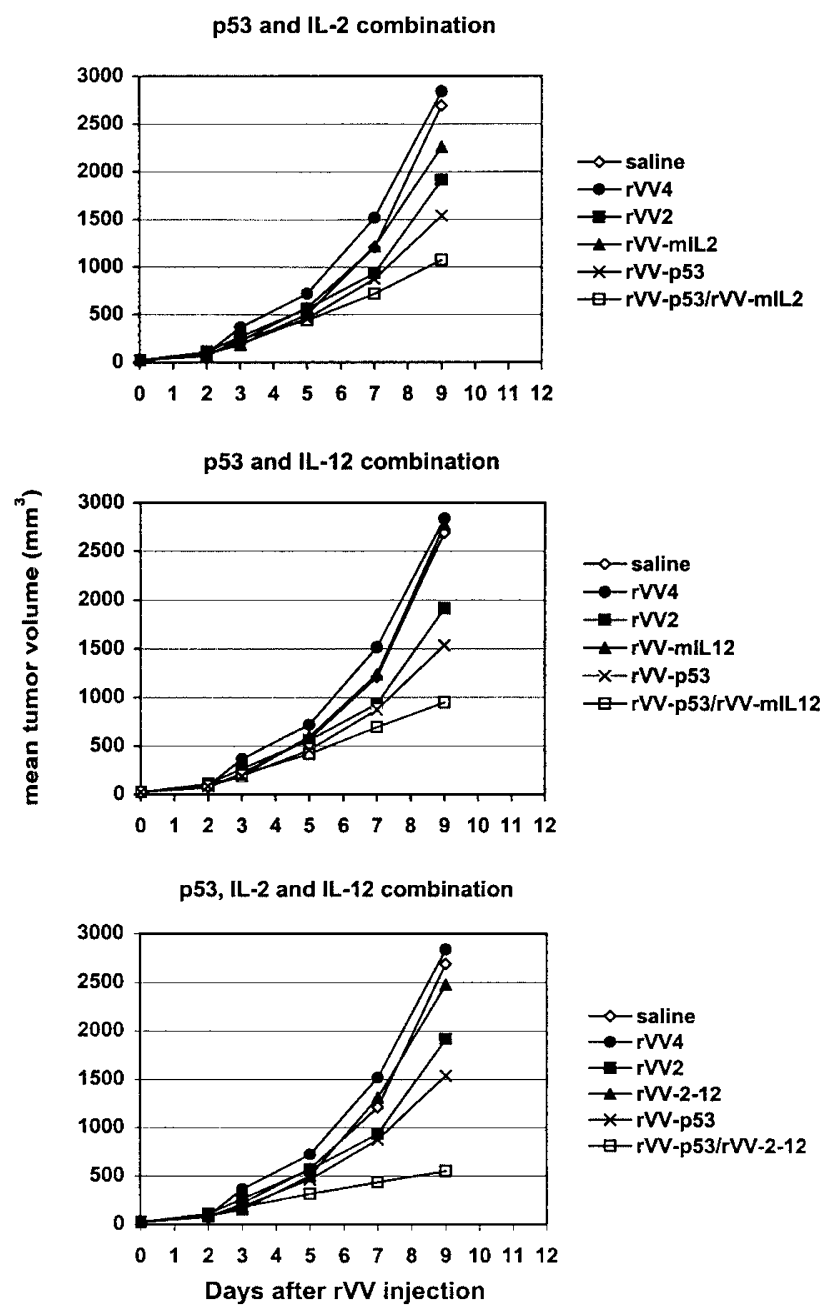

Figure 4. Tumor growth inhibition mediated by p53/cytokine combination therapy. Mice bearing s.c. C6 tumors of similar sizes were treated with recombinant VVs alone and in combination. Tumor growth in combination groups was compared with saline, virus control, and single agent treated groups. rVV-p53/rVV-2-12 and rVV-p53/rVV-mIL12 combination therapy resulted in significantly smaller tumor volumes $(P<.01$ and $P<.05$, respectively $)$ by day 9 after treatment compared to all other groups. 


\section{Data analysis}

The data were analyzed using one-way ANOVA and Tukey's HSD test (SPSS, Chicago, IL). A $P$ value of $<.05$ was considered to indicate significant differences among groups.

\section{RESULTS}

Interference in transgene expression by coinfection with two different $r V V s$ and p53 function

C6 cells infected with rVV-p53 or rVV-mIL2 overexpressed p53 or IL -2 with the peak of expression around 24-48 hours postinfection. However, the expression of these recombinant proteins was reduced when cells were co-infected with rVVp53 and rVV-mIL2 at the same MOI (Figs 1 and 2), although p53 function remained active. Indeed, the DNA fragmentation pattern induced by rVV-p53/rVV-mIL2 infection did not differ from that of rVV-p53 treatment. Cells infected by control virus (rVV2, rVV4) also showed a certain level of apoptosis that was substantially lower compared with the rVV-p53-treated cells (data not shown).

To determine the influence of high-dose virus on the infection and replication ability of the low-dose virus strain, C6 cells were coinfected with the rVV4/wtVV combination at a ratio of 1:100. After exposing the cells to viruses for 24 hours, the cells expressed a low level of rVV4-derived lacZ
(Fig 3), whereas infection of cells with rVV4 alone at the same MOI resulted in a significant increase in reporter expression $\left(111.9 \pm 1.31 \mathrm{rlu} / 10^{6}\right.$ cells $)$. These data indicate that high-dose virus can inhibit infection or replication of the low-dose virus if two viruses are combined.

\section{Effect of p53 and cytokine combination therapy}

This experiment was designed to test whether low doses of virus-mediated cytokine treatment can enhance the antitumor effect of p53. Athymic nude mice carrying established C6 tumor xenografts were i.t. treated with different p53/ cytokine combinations. On day 9 postinjection, animals treated with rVV-p53/rVV-mIL12 and rVVp53/rVV-2-12 showed significant tumor growth inhibition $(P<.05$ and $P<.01$, respectively) compared with those treated with a single construct (Fig 4). Combination therapy with rVVp53/rVV-mIL2, compared with rVV-p53 treatment, resulted in no significant increase in therapeutic effect $(P=.078)$. No significant differences in mean tumor volume were noted between rVV-p53 and control rVV2 groups $\left(1537.3 \pm 119.2\right.$ and $1745.5 \pm 136.9 \mathrm{~mm}^{3}$, respectively, on day 9), although in comparison with the saline control group they showed significantly reduced tumor growth.

Treatment with a single injection of 10 pfu of rVV-mIL2, rVV-mIL12, or rVV-2-12 did not result in tumor inhibition. rVV-mIL2 and rVV-mIL12 induced low, if any, cytokine toxicity. However, the construct rVV-2-12 expressing both

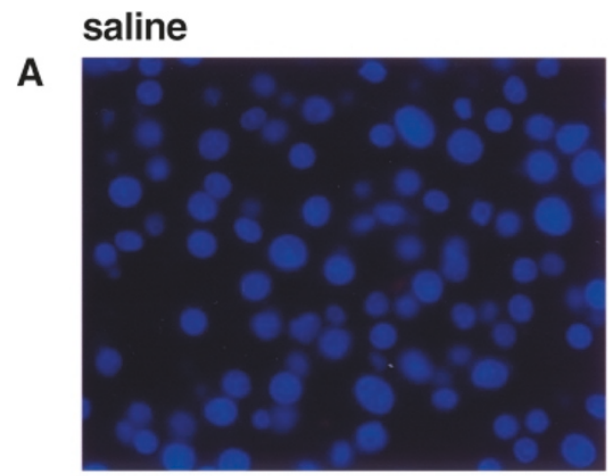

\section{rVV2}
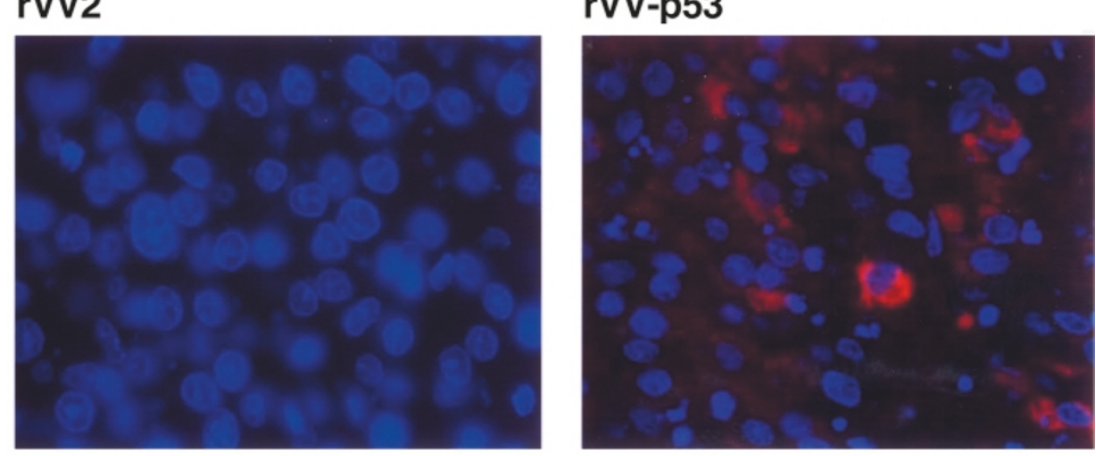

saline

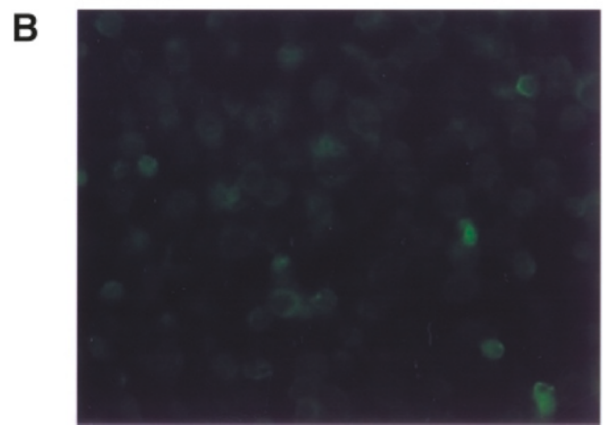

rVV2

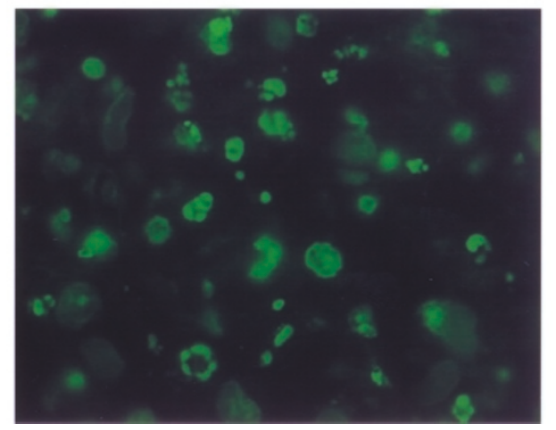

rVV-p53

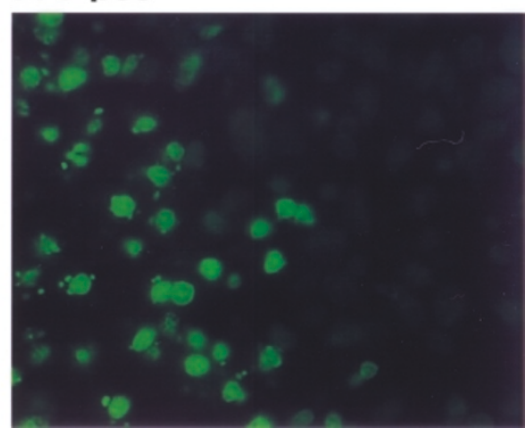

Figure 5. In situ detection of p53 expression and apoptosis. A: Paraffin-embedded tumor sections obtained from saline -, rVV2 control, and rVVp53-treated animals 9 days after virus injection were stained for p53 expression by immunohistochemistry. B: Tumor sections from these groups were also stained for apoptosis by TUNEL assay as described in Materials and Methods (magnification $\times 100$ ). 
cytokines resulted in death of $25 \%$ of the animals by days $5-$ 6 after treatment and $10 \%$ weight loss in most of the others. Interestingly, in the $\mathrm{rVV}-\mathrm{p} 53 / \mathrm{rVV}-2-12$ combination group, all animals survived and gained weight until the end of the study.

$r V V$-mediated production of recombinant proteins in tumors

Overexpressed p53 protein could be detected by immunohistochemistry at least 9 days after injection of rVV-p53 or p53/cytokine expressing combination viruses (Fig 5A). A strong signal was mostly found around or in the necrotic areas. The expression of p53 was not impaired after combined p53/cytokine therapy. Tumors treated with the control rVV2 virus showed a negative result.

On day 4 after virus injection, IL-2 expression was detected in tumors from two of four animals treated with $\mathrm{rVV}-2-12$ (18.3 and $3.4 \mathrm{ng} / \mathrm{g}$ tumor, respectively) and in one of four animals treated with $\mathrm{rVV}-\mathrm{p} 53 / \mathrm{rVV}-2-12$ (5.67 $\mathrm{ng} / \mathrm{g}$ tumor). On day 9 , only one animal treated with rVV-
p53/rVV-2 - 12 showed IL-2 expression in tumor $(6.6 \mathrm{ng} / \mathrm{g}$ tumor).

IL-12 was expressed in tumors of almost all animals treated with rVV-mIL12, rVV-2-12, rVV-p53/rVVmIL12, and rVV-p53/rVV-2-12, reaching the highest level, $57.3 \mathrm{ng} / \mathrm{g}$ tumor, on day 4 . Only one half of the animals expressed the cytokine on day 9 , with the highest value being $41.6 \mathrm{ng} / \mathrm{g}$ tumor.

\section{Apoptosis induced by recombinant $\mathrm{VV}$}

On day 9 after virus injection, apoptotic cells were detected by TUNEL staining in rVV2, rVV-p53, and p53/cytokine-treated groups (Fig 5B). These cells exhibited apoptotic morphology, containing strongly labeled condensed nuclei and micronuclei. TUNEL-positive cells were seen mostly around the necrotic tumor areas. Surprisingly, no difference was observed in tumor cell apoptosis between control rVV2 and rVV-p53 groups. Staining of saline-treated tumor cells showed few apoptotic cells.

Table 1. Leukocyte Populations in Peripheral Blood ANOVA: $P<.05$ for leukocytes and MNC on days 4 and $9 ; \boldsymbol{P}<.001$ for NK cells on days 4 and 9

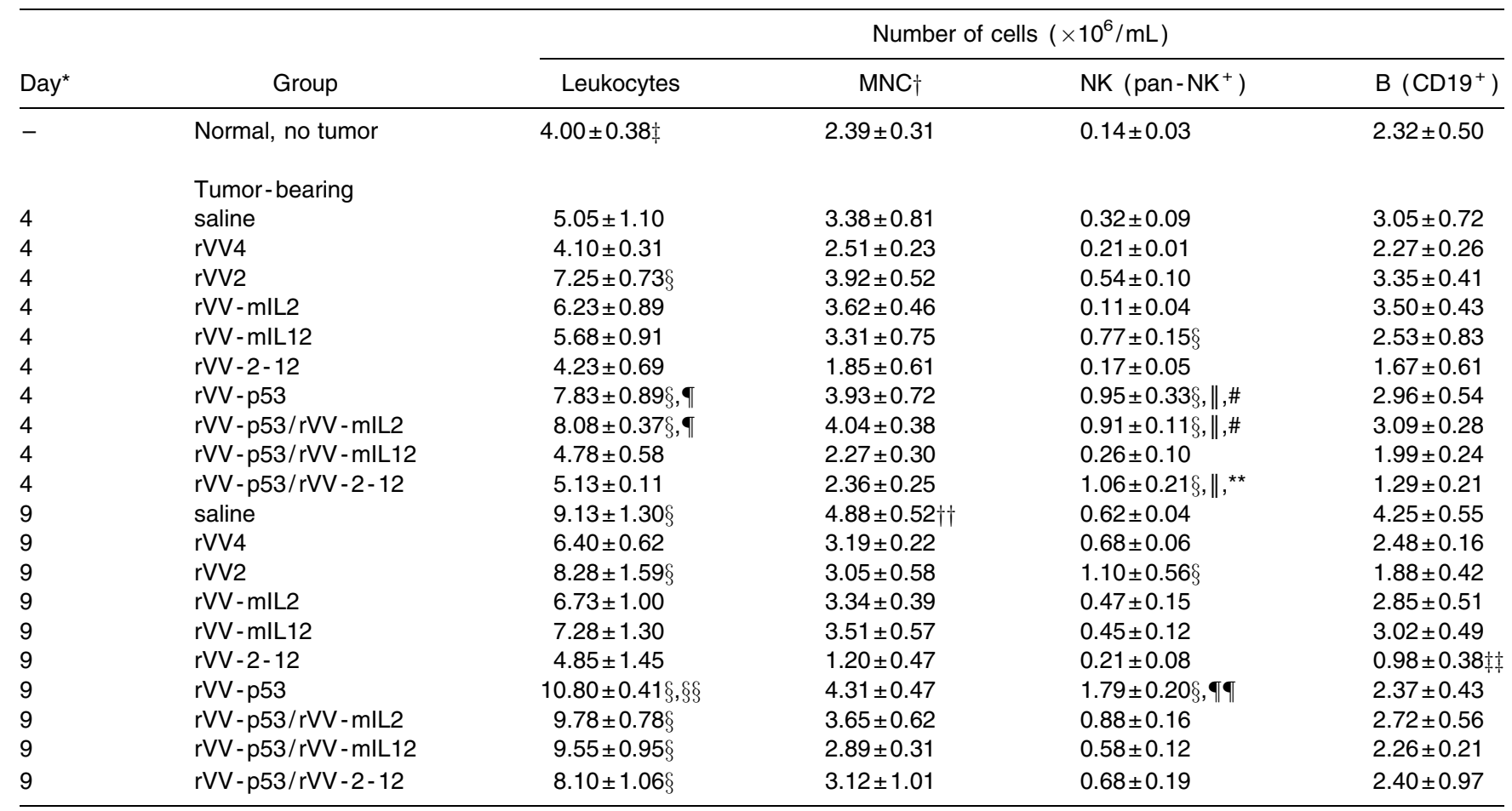

*Number of days after treatment. $\dagger$ MNC: mononuclear cells.

$\ddagger$ All data are reported as mean \pm SEM.

$\S P<.05$ versus no tumor.

$\uparrow P<.05$ versus rVV4 and rVV-2-12 on day 4.

$\| P<.05$ versus rVV4, rVV-mIL2, and rVV-2-12 on day 4.

$\# P<.05$ versus rVV4, rVV-mIL2, rVV-2-12, and rVV-p53/rVV-mIL12 on day 4.

${ }^{*} P<.05$ versus saline, rVV4, rVV-mIL2, rVV-2-12, and rVV-p53/rVV-mIL12 on day 4.

$\dagger \dagger P<.05$ versus no tumor and rVV-2-12 on day 9 .

$\ddagger \ddagger P<.05$ versus saline on day 9 .

$\S \S P<.05$ versus $\mathrm{rVV}-2-12$ on day 9 .

\ $9 P<.05$ versus all other groups on day 9 except rVV2 and rVV-p53/rVV-mIL2. 
Table 2. Leukocyte Populations in Spleen ANOVA: $P<.05$ for leukocytes and NK cells on days 4 and $9 ; P<.01$ for MNC and B cells on day 9

\begin{tabular}{|c|c|c|c|c|c|}
\hline \multirow[b]{2}{*}{ Day* } & \multirow[b]{2}{*}{ Group } & \multicolumn{4}{|c|}{ Number of cells $\left(\times 10^{6} / \mathrm{mL}\right)$} \\
\hline & & Leukocytes & $\mathrm{MNC} \dagger$ & NK $\left(\right.$ pan $\left.-\mathrm{NK}^{+}\right)$ & $\mathrm{B}\left(\mathrm{CD} 19^{+}\right)$ \\
\hline- & Normal, no tumor & $13.77 \pm 1.15 \ddagger$ & $10.07 \pm 0.65$ & $0.79 \pm 0.11$ & $9.74 \pm 0.60$ \\
\hline & Tumor-bearing & & & & \\
\hline 4 & saline & $19.35 \pm 3.67$ & $14.10 \pm 2.72$ & $1.41 \pm 0.28$ & $12.62 \pm 2.45$ \\
\hline 4 & rVV4 & $21.08 \pm 3.81$ & $15.11 \pm 2.60$ & $1.40 \pm 0.32$ & $13.54 \pm 2.35$ \\
\hline 4 & rVV2 & $25.83 \pm 2.47$ & $19.53 \pm 2.00$ & $1.54 \pm 0.19$ & $17.79 \pm 1.79$ \\
\hline 4 & $\mathrm{rVV}-\mathrm{mIL} 2$ & $21.35 \pm 2.71$ & $15.74 \pm 2.06$ & $1.13 \pm 0.07$ & $14.48 \pm 2.01$ \\
\hline 4 & rVV-mIL12 & $21.28 \pm 1.63$ & $15.84 \pm 1.09$ & $0.76 \pm 0.19$ & $15.02 \pm 1.06$ \\
\hline 4 & $r V V-2-12$ & $18.05 \pm 1.00$ & $12.84 \pm 0.90$ & $0.62 \pm 0.23$ & $12.16 \pm 0.80$ \\
\hline 4 & rVV-p53 & $28.70 \pm 3.02$ & $21.17 \pm 2.31$ & $2.41 \pm 0.13 \S$ & $18.63 \pm 2.30$ \\
\hline 4 & rVV-p53/rVV-mIL2 & $22.25 \pm 1.88$ & $15.81 \pm 1.75$ & $1.57 \pm 0.19$ & $14.12 \pm 1.60$ \\
\hline 4 & rVV-p53/rVV-mIL12 & $28.23 \pm 7.56$ & $20.31 \pm 5.90$ & $1.57 \pm 0.47$ & $18.67 \pm 5.44$ \\
\hline 4 & rVV-p53/rVV-2-12 & $30.45 \pm 7.68 \S$ & $21.53 \pm 5.70$ & $1.23 \pm 0.37$ & $20.25 \pm 5.65$ \\
\hline 9 & saline & $29.98 \pm 1.88$ & $20.21 \pm 1.45$ & $1.38 \pm 0.29$ & $19.40 \pm 1.24$ \\
\hline 9 & rVV4 & $30.63 \pm 3.30$ & $19.82 \pm 1.79$ & $1.60 \pm 0.03$ & $18.06 \pm 1.76$ \\
\hline 9 & rVV2 & $41.60 \pm 7.09 \S$ & $28.70 \pm 4.34 \S$ & $1.70 \pm 0.49$ & $26.51 \pm 3.99 \S$ \\
\hline 9 & rVV-mIL2 & $24.03 \pm 4.93$ & $14.97 \pm 3.82$ & $1.12 \pm 0.50$ & $13.68 \pm 3.29$ \\
\hline 9 & rVV-mIL12 & $43.30 \pm 3.56 \S$ & $21.62 \pm 2.34$ & $1.17 \pm 0.19$ & $20.19 \pm 2.19$ \\
\hline 9 & $r V V-2-12$ & $9.45 \pm 2.059$ & $6.53 \pm 2.17 \|$ & $0.08 \pm 0.01 \#$ & $6.41 \pm 2.16$ \\
\hline 9 & rVV-p53 & $43.38 \pm 0.75 \oint$ & $28.19 \pm 3.67 \S$ & $1.46 \pm 0.14$ & $26.49 \pm 3.57$ \\
\hline 9 & rVV-p53/rVV-mIL2 & $36.10 \pm 2.94 \S$ & $23.65 \pm 2.36$ & $1.32 \pm 0.20$ & $22.18 \pm 2.34$ \\
\hline 9 & rVV-p53/rVV-mIL12 & $32.85 \pm 3.23 \S$ & $23.18 \pm 2.46$ & $1.81 \pm 0.37$ & $21.18 \pm 213$ \\
\hline 9 & $r V V-p 53 / r V V-2-12$ & $38.40 \pm 10.32 \S$ & $25.69 \pm 7.24 \S$ & $1.04 \pm 0.29$ & $24.35 \pm 6.89 \S$ \\
\hline
\end{tabular}

*Number of days after treatment.

$\dagger$ MNC: mononuclear cells.

$\ddagger$ All data are reported as mean \pm SEM.

$\S P<.05$ versus no tumor.

ฯ $P<.05$ rVV2, rVV-mIL12, rVV-p53, rVV-p53/rVV-mIL2, and rVV-p53/rVV-2-12 on day 9.

$\| P<.05$ versus rVV2 and rVV - p53 on day 9.

$\# P<.05$ versus $\mathrm{rVV}-\mathrm{p} 53 / \mathrm{rVV}-\mathrm{mIL} 12$ on day 9.

Characterization of blood and spleen leukocytes by flow cytometry

The total number of leukocytes was consistently higher in the blood from all tumor-bearing mice compared to control animals with no tumor (Table 1). However, statistically significant increases were found only for rVV2, rVV-p53, and rVV-p53/rVV-mIL2 groups on day 4 . By day $9, \mathrm{rVV} 2$ group and all four groups treated with high-dose $\left(2 \times 10^{7}\right.$ pfu) recombinant constructs containing p53 as well as the saline-treated control group produced increase in the total number of leukocytes. In the spleen, total leukocyte counts were increased in most of the tumor-bearing groups by day 9 compared to the normal control group (Table 2). The most striking exception was the group treated with rVV-2-12 (day 9). There was no significant increase above normal in blood mononuclear cells in all virus - treated groups at both time points (Table 1). Splenic mononuclear cell numbers were above normal only on day 9 in mice treated with rVV2, rVV-p53, and rVV-p53/rVV-2-12.

On day 4 after a single i.t. injection of rVV-p53/rVV-212 , analysis of blood (but not spleen) samples showed a distinct increase in both the percentages and numbers of the NK cell population as compared with nearly all other treatment groups, as well as normal nontumor-bearing and saline-injected controls $(P<.05$; Tables 1 and 2 and Figs 6 and 7). By day 9, the NK cell increase induced by rVV-p53/ rVV-2 - 12 was no longer evident. rVV-p53 treatment alone enhanced the NK cell population in the blood (not spleen) in relation to nearly all of the other groups at both time points (Tables 1 and 2 and Figs 6 and 7). A substantial decrease in both the percentages and numbers of the NK-cell population was observed in spleens of rVV-2-12-treated animals on day 9 (Fig 7); relatively low number of NK cells was found in blood of rVV-2-12-treated animals as well. It may be related to the cytokine toxicity-related change induced by the combination of IL-2 and IL-12. Interestingly, a significant decrease was not found when the two cytokinecontaining constructs were combined with rVV-p53.

There were few significant differences observed in B-cell numbers in both the blood and spleen (Tables 1 and 2). The most dramatic observations include the low counts in the rVV-2-12-treated group and the relatively high counts seen in the spleens from rVV2, rVV-p53, and rVV-p53/rVV-212 groups on day 9 . Thus, the changes in $\mathrm{B}$-cell percentages (Figs 6 and 7) that were especially striking in the blood on day 4 are likely to reflect fluctuations in other cell types.

The number of Mac $-1^{+}$cells was greatly elevated in both the blood and spleen on day 9 after high-dose virus $\left(2 \times 10^{7}\right.$ pfu) treatment (rVV2 and all four p53-containing con- 
structs), as compared with the normal nontumor control group (Table 3 ). The percentages of these cells in the blood (primarily neutrophils and monocytes) doubled in almost all high-dose $\left(2 \times 10^{7} \mathrm{pfu}\right) \mathrm{rVV}$-treated animals on days 4 and 9 (Fig 6), indicating that phagocytic cell activation and/or recruitment was caused by high-dose application of the VV vector. However, spleen cell suspensions showed almost no significant differences in percentages of $\mathrm{Mac}^{-}{ }^{+}$cells (primarily macrophages) among groups at both time points of testing (Fig 7).

NKT cells $\left(\mathrm{NK} 1.1^{+}\right.$TCR $\left.-\beta^{+}\right)$, which have previously been reported to contribute to $\mathrm{IL}-12$-induced tumor inhibition, ${ }^{31}$ were detected at very low levels in the blood and spleen (Table 3). Nonetheless, a significant 3.1-fold
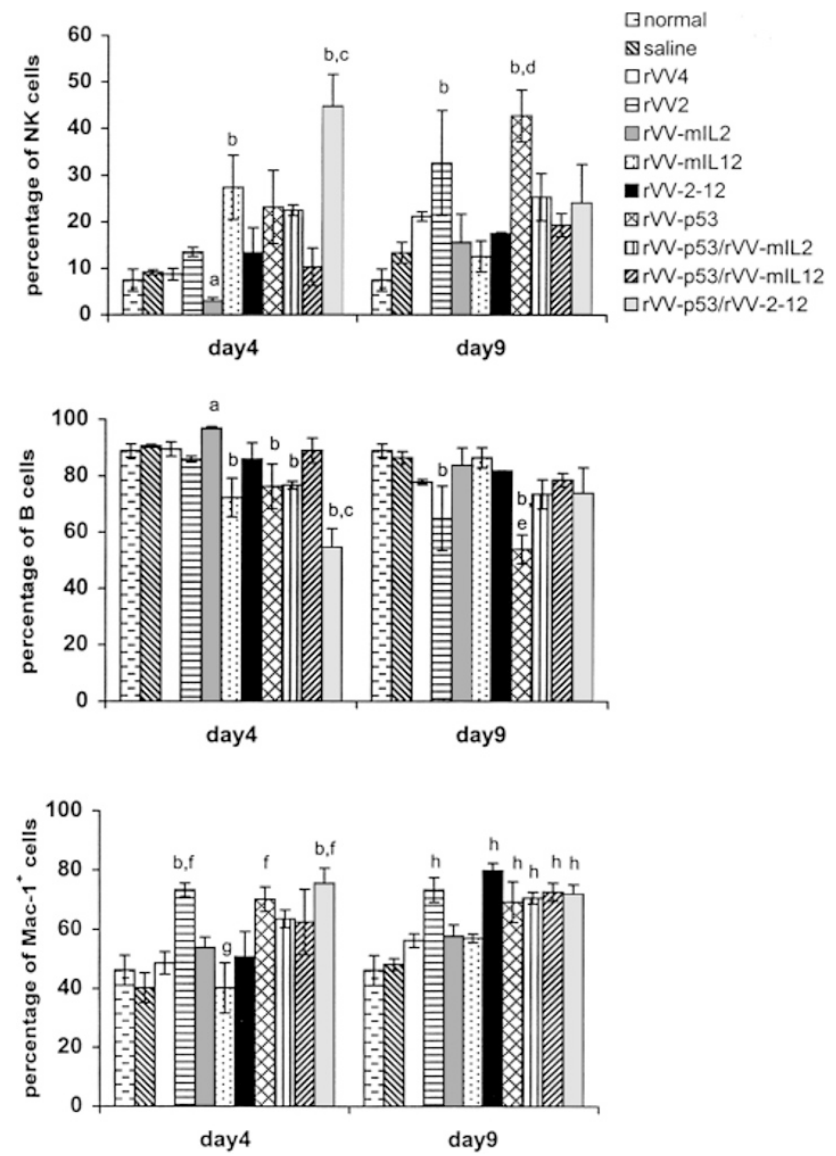

Figure 6. Percentages of $\mathrm{NK}, \mathrm{B}$, and $\mathrm{Mac}-1^{+}$cells in peripheral blood. The proportion of each cell type was determined by flow cytometry analysis. NK and B cell percentages are based on total lymphocytes; Mac- $1^{+}$cell percentages are based on total leukocytes. Each bar represents the mean \pm SEM per group. (a) $P<.05$ versus rVV-mIL12; (b) $P<.05$ versus normal; (c) $P<.05$ versus all other tumor-bearing groups except $\mathrm{rVV}$-mIL-12 on day 4; (d) $P<.05$ versus saline, rVV-mIL2, and rVV-mIL12 on day 9; (e) $P<.05$ versus saline, rVV-mIL2, and rVV-mIL12 on day 9; (f) $P<.05$ versus saline on day $4 ;$ (g) $P<.05$ versus rVV2, rVV-p53, and rVV-p53/rVV-2-12 on day 4; (h) $P<.05$ versus normal and saline on day 9 . NK cell ANOVA: $P<.001$ and $P<.01$ on days 4 and 9, respectively; $B$ and Mac $-1^{+}$cell ANOVA: $P<.001$ on both 4 and 9 days.
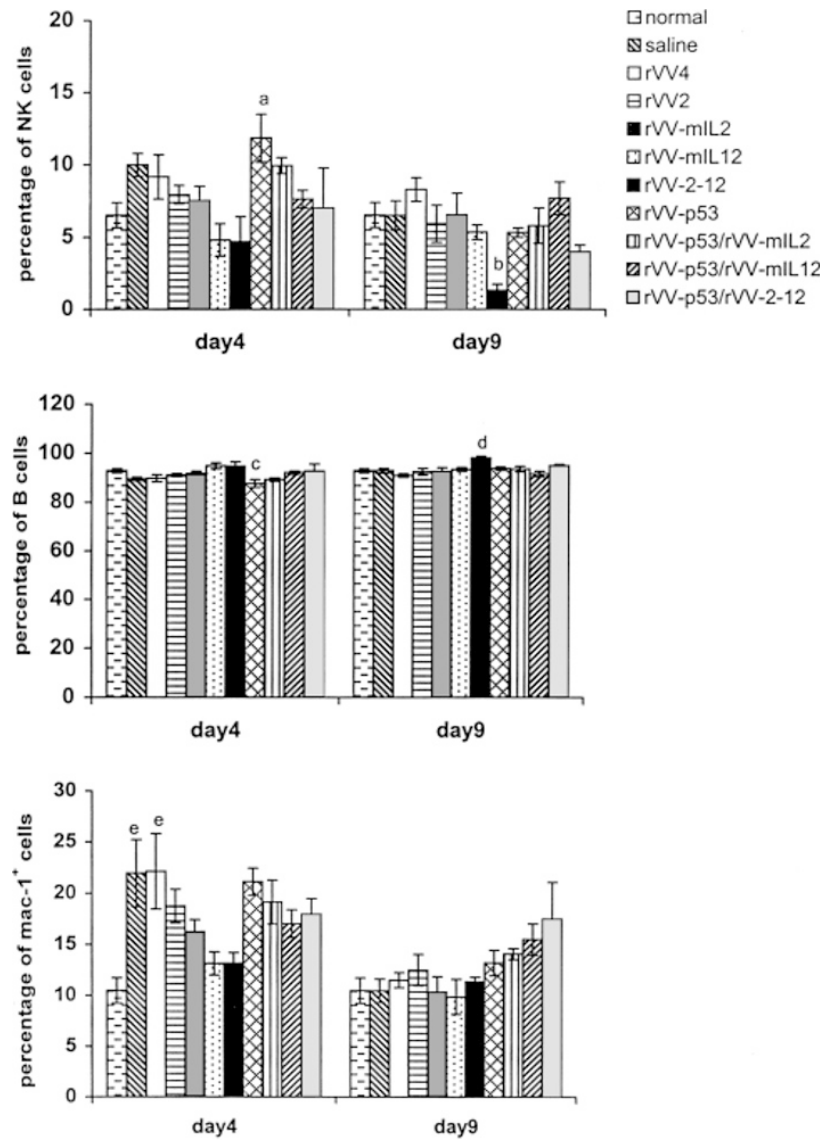

Figure 7. Percentages of NK, B, and Mac- $1^{+}$cells in the spleen. The proportion of each cell type was determined by flow cytometry analysis. NK and B cell percentages are based on total lymphocytes; Mac $-1^{+}$cell percentages are based on total leukocytes. Each bar represents the mean \pm SEM per group. (a) $P<.05$ versus $r V V-$ mIL12 and rVV-2-12 on day 4; (b) $P<.05$ versus normal, rVV4, and rVVp53/rVV-mIL12 on day 9; (c) $P<.05$ versus rVV-mIL12 and rVV2 - 12 on day 4 ; (d) $P<.05$ versus normal, rVV4, and rVV-p53/rVVmIL12 on day 9; (e) $P<.05$ versus normal. NK and B cell ANOVA: $P<.05$ on both 4 and 9 days; Mac $-1^{+}$- cell ANOVA: $P<.01$ on day 4 .

increase in the NKT cell number was noted in the blood from the mice treated with $\mathrm{rVV}-\mathrm{p} 53 / \mathrm{rVV}-2-12$ compared to the nontumor-bearing control group. At the same time, the level of this cell population in the blood was significantly higher than that for saline-injected and rVV-mIL12-treated mice. A similar NKT cell enhancement with $\mathrm{rVV}-\mathrm{p} 53 / \mathrm{rVV}-2-12$ treatment was observed in the spleen on day 4.

Intratumoral induction of IFN- $\gamma$ and TNF- $\alpha$

High production of IFN- $\gamma$ was measured only in some tumors on day 4 after treatments with rVV-mIL12 (891.4 $\mathrm{pg} / \mathrm{g}$ tumor $), \mathrm{rVV}-2-12$ (5000 pg/g tumor), rVV-p53/ $\mathrm{rVV}-\mathrm{mIL} 12$ ( $600 \mathrm{pg} / \mathrm{g}$ tumor $)$, and $\mathrm{rVV}-\mathrm{p} 53 / \mathrm{rVV}-2-12$ (1227.3 pg/g tumor), whereas all tumors treated with Hanks' saline, the two virus controls (rVV4, rVV2), rVVmIL2, and rVV-p53/rVV-mIL2 showed a low level of IFN$\gamma$ expression (less than $30 \mathrm{pg} / \mathrm{g}$ tumor). The striking 
Table 3. Mac $-1^{+}$and NKT Cells in Blood and Spleen ANOVA: $P<.001$ for Mac $-1^{+}$cells in blood on both days 4 and 9 ; $P<.05$ and $P<.001$ for Mac $-1^{+}$cells in spleen on days 4 and 9 , respectively; $P<.01$ for NKT cells in blood on day $9, P<.01$ and $P<.05$ in spleen on both days 4 and 9 , respectively

\begin{tabular}{|c|c|c|c|c|c|}
\hline \multirow[b]{3}{*}{ Day* } & \multirow[b]{3}{*}{ Group } & \multicolumn{4}{|c|}{ Number of cells } \\
\hline & & \multicolumn{2}{|l|}{ Blood } & \multicolumn{2}{|c|}{ Spleen } \\
\hline & & $\operatorname{Mac}-1^{+}\left(\times 10^{6} / \mathrm{mL}\right)$ & NKT $\left(\times 10^{4} / \mathrm{mL}\right)$ & $\operatorname{Mac}-1^{+}\left(\times 10^{6} / \mathrm{mL}\right)$ & NKT $\left(\times 10^{4} / \mathrm{mL}\right)$ \\
\hline- & Normal no tumor & $1.59 \pm 0.13 \dagger$ & $0.95 \pm 0.16$ & $1.55 \pm 0.33$ & $4.87 \pm 0.44$ \\
\hline 4 & $\begin{array}{l}\text { Tumor-bearing } \\
\text { saline }\end{array}$ & $1.14 \pm 0.38$ & $3.91+2.42$ & $3.25 \pm 1.12$ & $10.7 \pm 3.14$ \\
\hline 4 & rVV4 & $0.96 \pm 0.16$ & $0.32 \pm 0.09$ & $3.73 \pm 1.00$ & $10.5 \pm 2.36$ \\
\hline 4 & rVV2 & $3.19 \pm 0.28 \ddagger$ & $0.92 \pm 0.15$ & $3.53 \pm 0.55$ & $9.07 \pm 1.30$ \\
\hline 4 & rVV-mIL2 & $1.99 \pm 0.55$ & $0.61 \pm 0.06$ & $2.48 \pm 0.39$ & $6.15 \pm 0.91$ \\
\hline 4 & rVV-mIL12 & $1.07 \pm 0.26$ & $1.30 \pm 0.92$ & $2.14 \pm 0.17$ & $7.84 \pm 1.75$ \\
\hline 4 & $r V V-2-12$ & $1.05 \pm 0.31$ & $0.32 \pm 0.14$ & $1.73 \pm 0.11$ & $8.38 \pm 1.45$ \\
\hline 4 & rVV-p53 & $3.41 \pm 0.83 \S, 9$ & $0.61 \pm 0.10$ & $4.53 \pm 0.34 \S$ & $9.49 \pm 1.77$ \\
\hline 4 & rVV-p53/rVV-mIL2 & $2.67 \pm 0.46$ & $1.01 \pm 0.17$ & $2.88 \pm 0.53$ & $9.31 \pm 1.49$ \\
\hline 4 & rVV-p53/rVV-mIL12 & $1.65 \pm 0.49$ & $1.13 \pm 0.12$ & $3.76 \pm 0.98$ & $12.3 \pm 3.91$ \\
\hline 4 & rVV-p53/rVV-2-12 & $2.38 \pm 0.43$ & $2.84 \pm 1.69$ & $4.40 \pm 1.15$ & $17.4 \pm 1.59 \S, \|$ \\
\hline 9 & saline & $4.33 \pm 0.67$ & $0.89 \pm 0.09$ & $3.02 \pm 0.32$ & $13.3 \pm 2.78$ \\
\hline 9 & rVV4 & $3.56 \pm 0.43$ & $1.69 \pm 0.24$ & $3.35 \pm 0.18$ & $15.9 \pm 2.38$ \\
\hline 9 & rVV2 & $6.01 \pm 1.32 \S$ & $1.31 \pm 0.29$ & $4.93 \pm 0.95 \S$ & $29.5 \pm 6.55$ \\
\hline 9 & rVV-mIL2 & $3.82 \pm 0.61$ & $1.83 \pm 0.68$ & $2.59 \pm 0.87$ & $11.1 \pm 2.11$ \\
\hline 9 & rVV-mIL12 & $4.06 \pm 0.84$ & $1.09 \pm 0.13$ & $4.24 \pm 0.99$ & $32.9 \pm 18.9$ \\
\hline 9 & rVV-2-12 & $3.77 \pm 1.04$ & $0.99 \pm 0.21$ & $1.04 \pm 0.26$ & $14.2 \pm 0.06$ \\
\hline 9 & rVV-p53 & $7.03 \pm 1.07 \S$ & $2.12 \pm 0.57$ & $5.55 \pm 0.50 \S,{ }^{* *}$ & $40.1 \pm 10.8 \S$ \\
\hline 9 & rVV-p53/rVV-mIL2 & $6.63 \pm 0.37 \S$ & $1.46 \pm 0.21$ & $4.95 \pm 0.55 \S$ & $23.4 \pm 2.28$ \\
\hline 9 & rVV-p53/rVV-mIL12 & $6.81 \pm 0.80 \S$ & $1.86 \pm 0.35$ & $5.02 \pm 0.86 \S$ & $31.1 \pm 6.90$ \\
\hline 9 & $r V V-p 53 / r V V-2-12$ & $5.49 \pm 0.62 \S$ & $2.96 \pm 0.54 \S, \dagger \dagger$ & $5.22 \pm 1.53 \S$ & $27.6 \pm 7.38$ \\
\hline
\end{tabular}

*Number of days after treatment.

$\dagger$ All data are reported as mean \pm SEM.

$\ddagger P<.05$ versus saline, rVV4, rVV-mIL12, and rVV-2-12 on day 4 .

$\S P<.05$ versus no tumor.

$\Phi P<.05$ versus saline, rVV4, rVV-mIL12, and rVV-2-12 on day 4.

$\| P<.05$ versus $\mathrm{rVV}$ - mIL2 and $\mathrm{rVV}-\mathrm{mlL} 12$ on day 4.

$\# P<.05$ versus rVV4 on day 9.

${ }^{* \star} P<.05$ versus rVV $-2-12$ on day 9 .

$\dagger \dagger P<.05$ versus saline and rVV-mIL12 on day 9.

difference in IFN $-\gamma$ expression after treatments that included IL-12 versus those that included IL - 2 therapy supports the premise that induction of IFN $-\gamma$ is a characteristic feature of IL - 12 therapy.

A 6 -fold or greater increase in TNF - $\alpha$ expression was detected in one to three of four tumors tested per group following $\mathrm{rVV}-2-12$ (74.1 pg/g tumor), $\mathrm{rVV}-\mathrm{p} 53 / \mathrm{rVV}$ mIL2 (91.2 pg/g tumor), rVV-p53/rVV-mIL12 (70.5 pg/ $\mathrm{g}$ tumor), and rVV-p53/rVV-2-12 (332.9 pg/g tumor) treatment compared with the Hanks' saline control, both virus controls, rVV-mIL2, and rVV-mIL12 groups, which had less than $10 \mathrm{pg} / \mathrm{g}$ tumor. Some increase was found in the rVV-p53 group (23.1 pg/g tumor) as well.

\section{DISCUSSION}

Use of VV, a poxvirus, may be advantageous for gene therapy compared to other virus vectors due to its wide host range, efficient infectivity, large cloning capacity, and strong promoter systems. Most of vaccinia vectors are lytic viruses, but attenuated, replication-deficient strains, and inactivated viruses that are unlikely to cause generalized infection have also been described. ${ }^{32} \mathrm{VV}$ has successfully been used as a vector for immunotherapy, ${ }^{33-35}$ although its potential remains to be investigated in various gene therapy models.

Combination gene therapy offers therapeutic advances through the additive or synergistic effect induced by two or more therapeutic genes. The $\mathrm{p} 53$, IL-2, and IL-12 proteins are well known to have potent antitumor properties in animal studies, as well as in clinical trials. Here we evaluated whether combined VV-mediated delivery of these genes into tumors may elicit a synergistic antitumor effect by augmenting innate immune responses against C6 glioma cells and by inducing tumor cell apoptosis. A synergistic effect could be explained by several molecular mechanisms. First, antitumor action of p53 and IL - 12 may occur through inhibition of angiogenesis: (a) p53 has been shown to regulate the release of anti-angiogenic factors, such as thrombospondin $1 ;^{36}$ (b) over-expression of p53 may also inhibit the expression of vascular endothelial growth factor; ${ }^{37}$ and (c) IL-12 can inhibit angiogenesis by inducing 
IFN - $\gamma$, chemokine IP - 10, and NK cell killing of endothelial cells. ${ }^{23}$ Second, formation of apoptotic bodies by tumor cells because of overexpressed p53 may activate macrophages and induce a local inflammatory response, which can be amplified by VV-induced i.t. IL- 2 and/or IL- 12 production. Third, TNF - $\alpha$ released from activated macrophages and NK cells can induce hemorrhagic necrosis of tumors in vivo through destruction of tumor vasculature ${ }^{38}$ and trigger apoptosis in sensitive tumor types. ${ }^{39}$ Finally, IL - 2 and IL- 12 may enhance the immune response to $\mathrm{p} 53$ protein overexpressed in rVV-p53-infected tumor cells by activating NK cells, macrophages, and B cells. ${ }^{40}$

In this study, we demonstrated that the rVV-p53/rVVmIL12 and rVV-p53/rVV-2-12 combination therapies with $2 \times 10^{7}$ pfu of rVV-p53 and 10 pfu of cytokine-expressing viruses induced a statistically significant inhibition of tumor growth as compared with single agent treatment alone. In contrast, we did not observe marked reduction of tumor volume after $\mathrm{rVV}-\mathrm{p} 53 / \mathrm{rVV}$-mIL2 treatment, suggesting that the low dose (10 pfu) of the IL-2-expressing virus was insufficient to confer an antitumor effect.

rVV-p53/rVV-2-12 therapy, which showed greatest tumor inhibitory effect, induced substantial increases of NK cells in the blood on day 4, but not at later time point, suggesting that early proliferation of the NK cells may have played an important role in the observed antitumor effect. In addition, the increase of NKT cells from mice treated with $\mathrm{rVV}-\mathrm{p} 53 / \mathrm{rVV}-2-12$ indicates that this cell population may also have participated, at least to some extent, in slow tumor progression. The high level of IFN $-\gamma$ detected in tumors following $\mathrm{rVV}-\mathrm{p} 53 / \mathrm{rVV}-2-12$ treatment may indicate the local activation of NK cells. Previously, it has been shown that the combination of IL- 2 and IL- 12 provides a strong stimulus for IFN $-\gamma$ production by NK cells. ${ }^{41,42}$ However, locally induced IFN- $\gamma$ expression, which has been demonstrated to stimulate the secretion of other antitumor factors and inhibit the angiogenesis of the tumor, ${ }^{43}$ is necessary but not sufficient for effective tumor therapy. ${ }^{42,44}$ Indeed, we also observed relatively high production of IFN $-\gamma$ in tumors of rVV-2-12-treated animals, but with no significant tumor growth retardation. The finding that TNF - $\alpha$, a major product of activated macrophages, was elevated in the tumors suggests that tumor-infiltrating macrophages may have contributed to the antitumor effect of the combination therapy. However, further study is necessary to more specifically define the mechanisms of combined p53/ cytokine-mediated induction of NK and other nonspecific effector cells, IFN- $\gamma$ and TNF - $\alpha$ production, and the role of p53 in this process.

Unlike in vitro apoptosis study, we did not find the expected increase in apoptosis using rVV-p53-treated versus control virus-treated tumors, suggesting that leukocyte activation by a high dose of control viral vector may be an important factor in the observed apoptosis. The p53mediated antitumor effect may be explained by other mechanisms. A high level of NK cells after rVV-p53/ rVV-2-12 treatment and an increased i.t. TNF $-\alpha$ in p53/ cytokine-treated animals suggest an important role of p53 in antitumor effects. rVV-p53 alone also enhanced the numbers of total leukocytes, NK cells, and Mac- $1^{+}$cells, but the most intriguing increases were seen in NK cells on day 9. Overall, the data show that virus-mediated, overexpressed p53 alone can induce significant up-regulation of leukocyte populations that are known to have antitumor properties. The addition of rVV-2-12 to rVV-p53 resulted in a synergistic potentiation of NK cell population at an early stage.

It is interesting that the rVV-p53/rVV-2-12 combination decreased the cytokine-associated side effects caused by rVV-2-12, even though the dose of the rVV-2-12 was the same in both groups. Analysis of leukocyte populations generally showed low percentages and numbers of NK, B, $\mathrm{Mac}-1^{+}$, and NKT cell populations after $\mathrm{rVV}-2-12$ injection, which was not observed in the rVV-p53/rVV2-12 group. This finding suggests that the combination of p53 with cytokine gene therapy may be a safer strategy than cytokine therapy alone. It is not excluded that an increase in the ratio of rVV-2-12 to rVV-p53 in combination therapy could result in a greater therapeutic effect.

In summary, combined rVV-p53/rVV-2-12 and rVVp53/rVV-mIL12 treatments elicited a significant antitumor effect in the nude mouse s.c. C6 glioma model. Under most conditions, the combination treatments were administered with no detectable toxicity. The data also show that

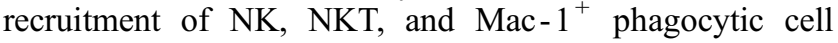
populations may account, at least partly, for the therapeutic effect. In our future studies, the combination strategy will be tested in a syngeneic brain tumor model following orthotopic implantation of glioma cells.

\section{ACKNOWLEDGMENTS}

We thank Glen M. Miller, Dong Won Kim, Jun Li, Xiao Wen Mao, and Erik Zendejas for assistance in the animal study. We are grateful to Drs. Susan Parker and Richard C. Mulligan for providing plasmids encoding IL-2 and IL-12.

This work was sponsored by the U.S. Department of the Army and the National Medical Technology Testbed. The view, opinions, and/or findings contained in this report are those of the authors and should not be construed as a position, policy, decision, or endorsement of the Federal Government or the National Medical Technology Testbed.

\section{REFERENCES}

1. Dietrich PY, Walker PR, Saas P, et al. Immunobiology of gliomas: new perspectives for therapy. Ann N Y Acad Sci. 1997; 824:124-140.

2. Lang FF, Miller DC, Pisharody S, et al. High frequency of p53 protein accumulation without p53 gene mutation in human juvenile pilocytic, low-grade, and anaplastic astrocytomas. Oncogene. 1994;9:949-954.

3. Newcomb EW, Madonia WJ, Pisharody S, et al. A correlative study of p53 protein alteration and p53 gene mutation in glioblastoma multiforme. Brain Pathol. 1993;3:229-235.

4. Wang XW, Harris CC. p53 tumor-suppressor gene: clues to molecular carcinogenesis. J Cell Physiol. 1997;173:247-255.

5. Fujiwara T, Kagawa S, Ogawa N, et al. Recombinant virus mediated transfer of the wild-type p53 gene is a potent therapeutic strategy for human cancer. Hum Cell. 1996;9:25-30. 
6. Qazilbash MH, Xiao X, Seth P, et al. Cancer gene therapy using a novel adeno-associated virus vector expressing human wild-type p53. Gene Ther. 1997;4:675-682.

7. Kim J, Hwang ES, Kim JS, et al. Intraperitoneal gene therapy with adenoviral-mediated p53 tumor-suppressor gene for ovarian cancer model in nude mouse. Cancer Gene Ther. 1999;6:172-178.

8. Aspinall RJ, Lemoine NR. Gene therapy for pancreatic and biliary malignancies. Ann Oncol. 1999;10:188-192.

9. Gomez-Manzano C, Fueyo J, Kyritsis AP, et al. Characterization of p53 and p21 functional interactions in glioma cells en route to apoptosis. J Natl Cancer Inst. 1997;89:1036-1044.

10. Shinoura N, Muramatsu Y, Nishimura M, et al. Adenovirus mediated transfer of p33ING1 with p53 drastically augments apoptosis in gliomas. Cancer Res. 1999;59:5521-5528.

11. Timiryasova TM, Chen B, Haghighat $\mathrm{P}$, et al. Vaccinia virus mediated expression of wild-type p53 suppresses glioma cell growth and induces apoptosis. Int J Oncol. 1999;14:845-854.

12. Li H, Lochmuller H, Yong VW, et al. Adenovirus-mediated wild-type p53 gene transfer and overexpression induces apoptosis of human glioma cells independent of endogenous p53 status. J Neuropathol Exp Neurol. 1997;56:872-878.

13. Badie B, Drazan KE, Kramar MH, et al. Adenovirus-mediated p53 gene delivery inhibits 9L glioma growth in rats. Neurol Res. 1995;17:209-216.

14. Li H, Alonso-Vanegas M, Colicos MA, et al. Intracerebral adenovirus-mediated p53 tumor-suppressor gene therapy for experimental human glioma. Clin Cancer Res. 1999;5:637-642.

15. Timiryasova TM, Li J, Chen B, et al. Antitumor effect of vaccinia virus in glioma model. Oncol Res. 1999;11:133-144.

16. Lang FF, Yung WK, RajuU, etal. Enhancement of radiosensitivity of wild-type p53 human glioma cells by adenovirus-mediated delivery of the p53 gene. J Neurosurg. 1998;89:125-132.

17. Gridley DS, Andres ML, Li J, et al. Evaluation of radiation effects against C6 glioma in combination with vaccinia virus p53 gene therapy. Int J Oncol. 1998;13:1093-1098.

18. Dorigo O, Turla ST, Lebedeva S, et al. Sensitization of rat glioblastoma multiforme to cisplatin in vivo following restoration of wild-type p53 function. J Neurosurg. 1998;88:535-540.

19. Putzer BM, Bramson JL, Addison CL, et al. Combination therapy with interleukin-2 and wild-type p53 expressed by adenoviral vectors potentiates tumor regression in a murine model of breast cancer. Hum Gene Ther. 1998;9:707-718.

20. Addison CL, Bramson JL, Hitt MM, et al. Intratumoral coinjection of adenoviral vectors expressing IL-2 and IL-12 results in enhanced frequency of regression of injected and untreated distal tumors. Gene Ther. 1998;5:1400-1409.

21. Fernandez N, Levraud JP, Haddada $\mathrm{H}$, et al. High frequency of specific $\mathrm{CD}^{+}$T cells in the tumor and blood is associated with efficient local IL-12 gene therapy of cancer. J Immunol. 1999;162:609-617.

22. Gollob JA, Schnipper CP, Murphy EA, et al. The functional synergy between IL-12 and IL-2 involves p38 mitogenactivated protein kinase and is associated with the augmentation of STAT serine phosphorylation. J Immunol. 1999; 162:4472-4481.

23. Yao L, Sgadari C, Furuke K, et al. Contribution of natural killer cells to inhibition of angiogenesis by interleukin-12. Blood. 1999;93:1612-1621.

24. Palu G, Cavaggioni A, Calvi P, et al. Gene therapy of glioblastoma multiforme via combined expression of suicide and cytokine genes: a pilot study in humans. Gene Ther. 1999; $6: 330-337$

25. Okada H, Miyamura K, Itoh $\mathrm{T}$, et al. Gene therapy against an experimental glioma using adeno-associated virus vectors. Gene Ther. 1996;3:957-964.
26. Toda M, Martuza RL, Kojima $\mathrm{H}$, et al. In situ cancer vaccination: an IL-12 defective vector/replication-competent herpes simplex virus combination induces local and systemic antitumor activity. J Immunol. 1998;160:4457-4464.

27. Kikuchi T, Joki T, Akasaki Y, et al. Antitumor activity of interleukin 12 against interleukin 2 -transduced mouse glioma cells. Cancer Lett. 1999;135:47-51.

28. Parker JN, Gillespie GY, Love CE, et al. Engineered herpes simplex virus expressing IL-12 in the treatment of experimental murine brain tumors. Proc Natl Acad Sci USA. 2000; 97:2208-2213.

29. Chen B, Timiryasova TM, Haghighat P, et al. Low-dose vaccinia virus-mediated cytokine gene therapy of glioma. $J$ Immunother. 2000 (in press).

30. Benda P, Lightbody J, Sato G, et al. Differentiated rat glial cell strain in tissue culture. Science. 1968;161:370-371.

31. Kitamura $H$, Iwakabe $K$, Yahata $T$, et al. The natural killer $T$ (NKT) cell ligand alpha-galactosylceramide demonstrates its immunopotentiating effect by inducing interleukin (IL) - 12 production by dendritic cells and IL -12 receptor expression on NKT cells. J Exp Med. 1999;189:1121-1128.

32. Moss B. Genetically engineered poxviruses for recombinant gene expression, vaccination, and safety. Proc Natl Acad Sci USA. 1996;93:11341-11348.

33. Peplinski GR, Tsung K, Meko JB, et al. In vivo gene therapy of a murine pancreas tumor with recombinant vaccinia virus encoding human interleukin - 1 beta. Surgery. 1995;118:185-191.

34. Uzendoski K, Kantor JA, Abrams SI, et al. Construction and characterization of a recombinant vaccinia virus expressing murine intercellular adhesion molecule 1: induction and potentiation of antitumor responses. Hum Gene Ther. 1997;8:851-860.

35. Kaufman HL, Rao JB, Irvine KR, et al. Interleukin-10 enhances the therapeutic effectiveness of a recombinant poxvirus-based vaccine in an experimental murine tumor model. J Immunother. 1999;22:489-496.

36. Dameron KM, Volpert OV, Tainsky MA, et al. Control of angiogenesis in fibroblasts by $\mathrm{p} 53$ regulation of thrombospondin-1. Science. 1994;265:1582-1584.

37. Nishizaki M, Fujiwara $T$, Tanida $T$, et al. Recombinant adenovirus expressing wild-type p53 is antiangiogenic: a proposed mechanism for bystander effect. Clin Cancer Res. 1999;5:1015-1023.

38. Carswell EA, Old LJ, Russel RL, et al. An endotoxin induced serum factor that causes necrosis of tumors. Proc Natl Acad Sci USA. 1975;72:3600-3670.

39. Rubin BY, Smith LJ, Hellerman GR, et al. Correlation between anticellular and DNA fragmentation activities of TNF. Cancer Res. 1988;48:6006-6010.

40. Topalian SL. MHC class II restricted tumor antigens and the role of $\mathrm{CD}^{+} \mathrm{T}$ cells in cancer immunotherapy. Curr Opin Immunol. 1994;6:741-745.

41. Ross ME, Caligiuri MA. Cytokine-induced apoptosis of human natural killer cells identifies a novel mechanism to regulate the innate immune response. Blood. 1997;89:910918.

42. Brunda M, Luistro L, Hendrzak J, et al. Role of interferon - $\gamma$ in mediating the antitumor efficacy of interleukin-12. J Immunother. 1995;17:71-77.

43. Fathallah-Shaykh HM, Zhao LJ, Kafrouni AI, et al. Gene transfer of IFN $-\gamma$ into established brain tumors represses growth by antiangiogenesis. J Immunol. 2000;164:217-222.

44. Nastala CL, Edington HD, McKinney TG, et al. Recombinant IL-12 administration induces tumor regression in association with IFN- $\gamma$ production. J Immunol. 1994;153:1697-1706. 